Volume 11, Nomor 1, Mei 2019, pp 98 - 114 Copyright (C) 2017 Jurnal Akuntansi Maranatha, Program Studi Akuntansi, Fakultas Ekonomi,Universitas Kristen Maranatha. ISSN 2085-8698 | e-ISSN 2598-4977. http://journal.maranatha.edu

\title{
Faktor-faktor Iklan yang Dapat Menarik Penonton Untuk Menonton Iklan Skip-Ads di Youtube Sampai Selesai
}

\author{
Anita Chrishanti Puteri Tito \\ Fakultas Ekonomi Program Pascasarjana Magister Manajemen \\ (Universitas Katolik Parahyangan, Jl. Merdeka No 30 Bandung) \\ puteri.tito@yahoo.com \\ Claudy Gabriella \\ Fakultas Ekonomi Program Sarjana \\ (Universitas Katolik Parahyangan, Jl. Ciumbuleuit No 94 Bandung) \\ cgabriella50@gmail.com
}

\begin{abstract}
Along with the changing times, technology plays an important role in the marketing world. The increasing use of the internet has led to the shift of marketing using print media into online media. Deployment of marketing strategies can be found through various platforms such as websites and social media. One popular website is used as a means to market your product or service is YouTube. If someone is using YouTube certainly will often encounter many types of ads, but the most common and often comes up is true view in-stream ads that are usually will appear before the video starts. The ad will run for 5 seconds before it was finally has available options for in-skip.

The problem that occurs is the lack of enthusiastic viewers to watch ads are marked with the number of viewers that will be to skip even before watching the commercials and this becomes a problem that hurt the company because it can not deliver the message properly. Therefore, researcher will find out the factors that can make viewers watch ads up to completion that are divided by age and gender.

The method used in this study is exploratory research and based on the goals of this research it is an applied research because it will be used as a solution to solve the existing problems. The data collection will be done in two (2) methods: literature review and depth interview.

The results showed the existence of some differences and some similarities between groups that will be presented in tabular form, analysed in qualitative method.
\end{abstract}

Keyword: Online Advertising, YouTube, True View In-stream Ads, Exploratory Research, Depth Interview

\section{Pendahuluan}

Teknologi terus mengalami kemajuan dari waktu ke waktu termasuk penggunaan internet. Potensi pengguna internet yang semakin meningkat, menyebabkan industri iklan mulai beralih memasarkan produk maupun jasanya melalui internet. Kegiatan 
pemasaran kini mulai beralih ke kanal online dan mulai mengurangi penggunaan media cetak, televisi, dan radio. Pemasaran online menggunakan internet sebagai suatu tempat yang memudahkan perusahaan beradaptasi terhadap kebutuhan konsumen, mengurangi biaya transaksi dan membuat konsumen berpindah dari suatu perilaku yang berdasarkan waktu dan lokasi ke suatu perilaku yang tidak berdasarkan waktu dan tempat.(Watson et al., 2002).

Perusahaan dapat menggunakan berbagai macam platform sebagai sarana promosi seperti website, youtube, social media, blog, online advertising, dan lainlain.Youtube merupakan salah satu media yang paling banyak diminati untuk menaruh iklan dan memasarkan produk perusahaan. Terdapat beberapa jenis iklan yang beredar di YouTube, salah satunya yakni TrueView in-stream ads yang dikenal dengan sebutan skip-ads dikalangan masyarakat. Jenis iklan ini biasanya berdurasi antara 15 sampai 30 detik. Penonton memiliki pilihan untuk tetap menonton atau melewati iklan setelah 5 detik. TrueView in-stream ads akan muncul secara acak saat kita membuka video untuk ditonton, bisa muncul pada awal, tengah, dan akhir video.

Menjadi menarik untuk diteliti dan diketahui lebih dalam mengenai ketertarikan viewers untuk menonton iklan jenis TrueView in-stream ads hingga selesai. Ketertarikan ini didasarkan pada sebuah gejala yang menunjukkan bahwa adanya lack of interest dari viewers untuk menonton iklan tersebut. Ketika dilakukan pencarian mengenai pop-up iklan YouTube di Google, mayoritas artikel yang keluar pada pencarian adalah mengenai bagaimana acara menghilangkan iklan-iklan tersebut. Ini menunjukkan sedikitnya ketertarikan viewers YouTube untuk menonton iklan yang beredar tersebut.Sisi lainnya, perusahaan harus mengeluarkan biaya produksi untuk membuat iklan tersebut dan berharap bahwa iklan dapat menyampaikan informasi secara tepat, bahkan mampu menciptakan

penontonnya.

$$
\text { engagement }
$$

bagi

Perilaku seseorang dalam memilih jenis video yang ditonton di YouTube dipengaruhi oleh jenis kelamin. Berdasarkan pada data yang dilansir oleh Digiday pada situsnya yakni digiday.com disebutkan bahwa kategori video YouTube yang didominasi oleh wanita sebesar $89.31 \%$ adalah makeup \& cosmetics, disusul skin \& nail care sebesar $85.29 \%$, dan weight loss sebesar $61.14 \%$. Sedangkan untuk pria sebesar $94.62 \%$ seputar soccer, $94.42 \%$ strategy games, dan sebesar 94.21 Xbox. Tidak hanya jenis kelamin, golongan usia pun menentukan perilaku berbeda-beda saat menggunakan YouTube. Berdasarkan pada 29 responden usia muda yang ditanyakan, $89.7 \%$ responden menyatakan bahwa mereka tidak akan menonton iklan sampai selesai. Alasan yang paling banyak ditemui hal ini disebabkan oleh iklan yang kurang menarik, menghabiskan waktu, mengganggu, membosankan, tidak berguna, dan sebagainya. Berbeda dengan responden yang lebih dewasa, beberapa responden menyatakan bahwa mereka menunggu iklan sampai selesai karena tidak tahu bahwa iklan yang muncul bisa di skip. Sebagian lainnya mengatakan bahwa terkadang mereka akan menonton apabila iklan berguna dan berdampak bagi mereka, dan tidak sedikit yang menginginkan iklan yang edukatif atau memiliki pesan moral.

Penelitian ini bertujuan untuk mengetahui faktor-faktor iklan apa saja yang dapat menarik viewers (penonton) untuk menonton iklan true view in-stream ads di website YouTube hingga selesai berdasarkan usia dan jenis kelamin. Penelitian ini diharapkan dapat memberikan kontribusi teori mengenai unsur-unsur suatu iklan video yang efektif. Sedangkan secara praktik, diharapkan mampu memberikan sebuah solusi bagi perusahaan mengenai faktor-faktor pembuatan iklan yang efektif dan menarik sehingga membuat masyarakat luas tertarik untuk menonton iklan yang ditampilkan agar informasi dan pesan dapat 
tersampaikan dengan baik dan jelas, berdasarkan golongan usia.

\section{Identifikasi Masalah}

Adapun identifikasi masalah dari penelitian ini adalah sebagai berikut:

1. Faktor-faktor iklan apa yang dapat menarik viewers (penonton) untuk menonton iklan true view in-streamads di website YouTube sampai selesai berdasarkan golongan usia dan jenis kelamin?

\section{Tujuan dan Manfaat Penelitian}

Adapun tujuan dari penelitian ini adalah:

1. Mengetahui faktor-faktor iklan apa yang dapat menarik viewers (penonton) untuk menonton iklan true view in-streamads di website YouTube sampai selesai berdasarkan golongan usia dan jenis kelamin.

\section{Kerangka Teoritis}

\section{Iklan}

Iklan atau periklanan merupakan semua bentuk terbayar atas presentasi nonprobadi dan promosi ide, barang, atau jasa oleh sponsor yang jelas (Kotler dan Keller, 2009). Periklanan juga disebut sebagai suatu proses komunikasi yang bertujuan untuk membujuk atau menggiring orang untuk mengambil tindakan yang menguntungkan bagi pihak pembuat iklan (Durianto, dikutip oleh Theresia Intan, 2003). Fandy Tjiptono (yang dikutip oleh Widyatama) mengatakan bahwa iklan adalah bentuk komunikasi tidak langsung yang didasari pada informasi tentang keunggulan atau keuntungan suatu produk yang disusun sedemikian rupa sehingga menimbulkan rasa menyenangkan yang akan menguubah pikiran seseorang untuk melakukan pembelian. Pada dasarnya, periklanan merupakan suatu sarana untuk memperkenalkan, mengingatkan, serta membujuk konsumen agar tertarik terhadap produk yang ditawarkan.
Kotler (Kotler \& K.L, 2008) menyebutkan bahwa terdapat lima kelompok tujuan periklanan yakni pertama Informative Advertising, digunakan oleh perusahaan saat produk baru diluncurkan. Iklan digunakan untuk memperkenalkan produk tersebut, menginformaikan kegunaannya, dan memberitahukan penawaran yang diberikan oleh perusahaan kepada pasar. Kedua Persuasive Advertising, digunakan pada tahap persaingan yang dihadapi perusahaan. Tujuannya untuk menciptakan permintaan akan produk agar konsumen memiliki preferensi produk terhadap merek tersebut dan berujung pada transaksi pembelian. Ketiga, Comparison Advertising merupakan iklan yang bertujuan untuk membandingkan langsung produk perusahaan dengan produk dari merek pesaingnya sehingga menciptakan kesan lebih unggul, namun perusahaan harus memiliki bukti kuat untuk mendukung statement yang diberikan agar tidak diserang kembali oleh pesaingnya.Keempat, Reminder Advertising bertujuan untuk mengingatkan konsumen mengenai keberadaan suatu produk agar tetap menggunakannya.Kelima, Reinforcement Advertising, bertujuan untuk memberi dukungan kepada konsumen bahwa mereka telah mengambil keputusan pembelian yang tepat.Biasanya iklan jenis ini bersifat edukatif.

\section{Efektifitas Iklan}

AC Nielsen, sebuah perusahaan peneliti pemasaran mengembangkan sebuah model yang dapat menilai dan menganalisis apakah suatu iklan dapat dikatakan efektif atau tidak. Model ini kemudian dikenal sebagai teori EPIC yakni Emphaty, Persuasion, Impact, Communication (Durianto, 2003).Empathy merupakan keadaan mental yang membuat seseorang merasa dirinya pada keadaan perasaan atau pikiran yang sama dengan orang atau kelompok lain. Persuasion dilihat berdasarkan kemampuan pemasang iklan untuk memahami dampak iklan terhadap 
keinginan dan kebutuhan konsumen.Hal ini dilakukan untuk meningkatkan daya tarik suatu produk di mata konsumen. Aspek impact dapat dilihat pada hasil dari pemasangan iklan dengan mengetahui tingkat pengetahuan viewers mengenai produk setelah mereka menonton iklan tersebut. Sebuah iklan dikatakan efektif jika terdapat sebuah konten yang berbeda dari yang lain dan lebih menonjol untuk menimbulkan rasa penasaran dan ketertarikan untuk menontonnya. Aspek communication ingin melihat apakah sebuah iklan mampu dipahami oleh viewers. Sebuah iklan dikatakan berhasil dan sudah memiliki aspek komunikasi yang baik ketika mampu menyampaikan informasi secara tepat sehingga viewers memahami informasi yang diberikan pada saat menonton iklan tersebut.

\section{Komponen Iklan}

Burke dan Edell (1989) dan Escalas dan Rutgers (2003) yang dikutip dalam Wei, Jerome, dan Shan (2010), menyebutkan tiga komponen yang harus dimiliki oleh sebuah iklan yakni multimedia, pictures, dan content. Pertama multimedia merupakan sebuah animasi disertai dengan gambar yang bergerak dan grafik untuk meningkatkan tampilan dari pesan yang persuasive (Yoo et al., 2004). Kedua, pictures merupakan sebuah gambar yang bisa membuat iklan menjadi lebih menarik (Taylor et al, 2008).Kumar, 2008 menambahkan bahwa konsumen lebih tertarik ketika iklan mudah dipahami tanpa melibatkan teks dalam jumlah yang besar.Ketiga, content merupakan pesan singkat yang menentukan efektivitas sebuah iklan (Baltas, 2003).Pesan iklan yang mengandung informasi luas mengenai produk atau layanan cenderung menjadi daya tarik bagi konsumen (Adam, 20013).

\section{Daya Tarik Iklan}

Daya tarik dalam sebuah iklan merupakan sebuah kemampuan untuk bisa menarik perhatian target pasar. Menurut Kotler dan
Amstrong (2011) yang dikutip oleh Widowati menyatakan bahwa daya tarik iklan memiliki tiga sifat: Meaningful (iklan harus mengandung sebuah makna mengenai manfaat-manfaat mengenai produk sehingga lebih menarik dan diinginkan oleh konsumen), Believeable (konsumen akan mendapatkan manfaat seperti yang sudah dijanjikan dalam pesan iklan), dan Distinctive (pesan iklan lebih baik dibandingkan iklan merek pesaing). Shimp (2003) mengatakan bahwa terdapat beberapa daya tarik yang sering digunakan dalam pembuatan iklan seperti endorser (peran pendukung), unsur humor, rasa takut dan rasa bersalah sebagai pengikat, daya tarik musik iklan, dan pemakaian unsur seksual dalam periklanan.

\section{Faktor Potensial yang Mempengaruhi Penyelesaian Iklan}

Krishnan dan Sitaraman (2013) menyebutkan terdapat tiga faktor yang mempengaruhi penonton menonton iklan sampai selesai:

1. Faktor yang berhubungan dengan iklan Iklan dan konten iklan diidentifikasikan berdasarkan keunikan namanya sebagai faktor utama.Posisi iklan berhubungan dengan letak iklan dalam video bisa diawal, tengah, dan akhir.Secara umum durasi iklan dalam penelitian ini adalah 15, 20, dan 30 detik.

2. Faktor yang berhubungan dengan video Konten merupakan faktor pertama dari sebuah video yang diidentifikasikan secara unik melalui urlnya.Faktor lainnya yakni durasi video yang digunakan untuk membedakan video pendek dengan video panjang. Menurut Interactive Advertising Bureau (IAB), video panjang berdurasi lebih dari 10 menit, sedangkan video pendek kurang dari 10 menit.

3. Faktor yang berhubungan dengan penonton

Seorang penonton secara unik dan rahasia diidentifikasikan berdasarkan Globally Unique Identifier (GIUD), 
dimana setiap penonton memiliki GUID yang berbeda-beda.Tidak hanya itu, terdapat tiga atribut lainnya dari seorang penonton yakni pertama lokasi geografis yang mempengaruhi perilaku menonton. Kedua, cara atau sikap penonton tersambung dengan internet dengan melihat pada alat yang digunakan dan tipe konektivitas seperti mobile, DSL, kabel, dan fiber. Ketiga, waktu dan frekuensi seorang penonton menonton iklan mencakup waktu dalam hari dan hari dalam minggu.

Tabel 1

Faktor Potensial yang Mempengaruhi Penyelesaian Iklan

\begin{tabular}{|c|c|c|}
\hline Type & Factor & Description \\
\hline \multirow{3}{*}{ Ad } & Content & $\begin{array}{l}\text { Defined by unique } \\
\text { name }\end{array}$ \\
\hline & Position & $\begin{array}{l}\text { Pre-roll, mid-roll, } \\
\text { post-roll }\end{array}$ \\
\hline & Length & $\begin{array}{l}\text { 15-, 20-, 30- } \\
\text { second }\end{array}$ \\
\hline \multirow{3}{*}{ Video } & Content & $\begin{array}{l}\text { Defined by unique } \\
\text { url }\end{array}$ \\
\hline & Length & $\begin{array}{l}\text { Short-form, Long- } \\
\text { form }\end{array}$ \\
\hline & Provider & $\begin{array}{l}\text { News, Movie, } \\
\text { Sports, } \\
\text { Entertainment }\end{array}$ \\
\hline \multirow{4}{*}{ Viewer } & Identity & $\begin{array}{l}\text { Defined by unique } \\
\text { GUID }\end{array}$ \\
\hline & Geography & $\begin{array}{l}\text { Country and } \\
\text { Continent }\end{array}$ \\
\hline & $\begin{array}{l}\text { Connection } \\
\text { Type }\end{array}$ & $\begin{array}{l}\text { Mobile, DSL, } \\
\text { Cable, Fiber }\end{array}$ \\
\hline & Temporal & Time of day, day \\
\hline
\end{tabular}

\begin{tabular}{|l|l|l|}
\hline & & of week \\
\cline { 2 - 3 } & Frequency & $\begin{array}{l}\text { Frequency of visits } \\
\text { to a site }\end{array}$ \\
\hline
\end{tabular}

Sumber : Krishnan \& Sitaraman

(2013)

\section{Metode Penelitian}

Metode yang akan digunakan dalam penelitian ini adalah exploratory research dimana penelitian bertujuan untuk mendapat pemahaman mendalam mengenai suatu masalah yang terjadi dengan cara mengambil sample dari populasi yang ada dan menggunakan depth interview terhadap responden yang memenuhi kriteria tertentu.

\section{Jenis Penelitian}

Berdasarkan tujuan yang ingin dicapai penelitian ini adalah applied research, dimana hasilpenelitian dapat memberi gambaran jelas mengenai masalah yang terjadi. Juga akan digunakan sebagai salah satu sarana untuk memecahkan masalah tersebut dengan memberi solusi apa yang harus dilakukan. Dalam penelitian ini adalah iklan di website YouTube agar dapat menarik viewer menontonnya hingga selesai.

\section{Populasi dan Sampel Penelitian}

Populasi untuk penelitian ini adalah setiap pengguna YouTube dan familiar terhadap iklan yang muncul di YouTube agar mampu memenuhi tujuan penelitian.Pemilihan sampel dalam penelitian ini menggunakan metode purposive sampling.Sampling dilakukan dengan cara mengambil responden yang merupakan pengguna aktif YouTube dan familiar dengan iklan skip ad yang sering muncul secara random pada website.

Digunakan pula teknik snowball sampling dengan cara melakukan wawancara mendalam kepada setiap responden yang memenuhi kriteria lalu mencari responden lain lagi sampai semakin 
banyak dan akan berhenti ketika sudah mulai terjadi replikasi atau pengulangan informasi (data homogen).Kemudian didapatkan jumlah sample akhir yang diambil adalah 39 orang.

\section{Metode Pengumpulan Data}

Teknik pengumpulan data yang akan digunakan adalah studi literatur dan depth interview. Studi literatur merupakan teknik yang digunakan untuk mengumpulkan teori berdasarkan sumber tertulis seperti buku, jurnal, artikel, website dan sebagainya. Sedangkan teknik depthinterview dilakukan secara terstruktur terhadap viewers YouTube berdasarkan golongan usia dan jenis kelamin untuk mendapatkan jawaban yang lebih jelas dan mencapai sasaran penelitian.

Tabel 2

Total Responden

\begin{tabular}{|c|c|c|c|c|}
\hline \multirow{2}{*}{$\begin{array}{c}\text { Jenis } \\
\text { Kelamin }\end{array}$} & $\begin{array}{c}12- \\
21\end{array}$ & $\begin{array}{c}22- \\
31\end{array}$ & $\begin{array}{c}32- \\
41\end{array}$ & $42-51$ \\
\hline Pria & 5 & 5 & 5 & 5 \\
\hline Wanita & 5 & 5 & 4 & 5 \\
\hline $\begin{array}{c}\text { Total } \\
\text { Responde } \\
\text { n }\end{array}$ & 10 & 10 & 9 & 10 \\
\hline
\end{tabular}

Sumber : Dokumen Penulis

\section{Operasionalisasi Variabel}

Tabel 3

Operasionalisasi Variabel

\begin{tabular}{|c|c|c|}
\hline Variabel & Konsep & Indikator \\
\hline \multirow{11}{*}{$\begin{array}{l}\text { Komponen- } \\
\text { komponen } \\
\text { iklan yang } \\
\text { mempengaruhi } \\
\text { pemirsa untuk } \\
\text { menyaksikan } \\
\text { iklan di } \\
\text { website } \\
\text { YouTube } \\
\text { hingga selesai }\end{array}$} & \multirow{11}{*}{$\begin{array}{l}\text { Memaparkan } \\
11 \text { Faktor } \\
\text { penting yang } \\
\text { harus } \\
\text { diperhatikan } \\
\text { saat } \\
\text { membuat } \\
\text { suatu iklan } \\
\text { agar pemirsa } \\
\text { menyaksikan } \\
\text { iklan hingga } \\
\text { selesai }\end{array}$} & $\begin{array}{l}\text { Pendukung } \\
\text { Iklan } \\
\text { (Endorser) } \\
\mathrm{X} 1\end{array}$ \\
\hline & & $\begin{array}{l}\text { Jalan Cerita } \\
\text { Iklan } \\
\text { X2 }\end{array}$ \\
\hline & & $\begin{array}{l}\text { Menarik } \\
\text { (Appealing) } \\
\text { X3 }\end{array}$ \\
\hline & & $\begin{array}{l}\text { Minat } \\
\text { (Interest } \\
\text { Value) X4 }\end{array}$ \\
\hline & & Bahasa X5 \\
\hline & & $\begin{array}{l}\text { Musik dan } \\
\text { Gambar } \\
\text { X6 }\end{array}$ \\
\hline & & $\begin{array}{l}\text { Kepercayaan, } \\
\text { Emosional, } \\
\text { dan } \\
\text { Pengetahuan } \\
\text { X7 }\end{array}$ \\
\hline & & $\begin{array}{l}\text { Bahan } \\
\text { Pembicaraan } \\
\text { (socialbility) } \\
\text { X8 }\end{array}$ \\
\hline & & $\begin{array}{l}\text { Animasi dan } \\
\text { Jingle X9 }\end{array}$ \\
\hline & & $\begin{array}{l}\text { Informatif } \\
\text { (Perceived } \\
\text { Informative } \\
\text { Value) X10 }\end{array}$ \\
\hline & & Quotes X11 \\
\hline
\end{tabular}




\section{Metode Analisis Data}

\section{Triangulasi}

Triangulasi merupakan metode yang digunakan sebagai sarana untuk menguji dan menjamin kebenaran data. Informasi dan data yang diperoleh akan dibandingkan dengan cara yang berbeda. Triangulasi akan dilakukan dengan memadukan wawancara mendalam dan studi literatur untuk menghindari terjadinya bias pada informasi dan data yang diperoleh.Wawancara juga akan dilakukan kepada informan/ responden yang berbeda untuk memastikan data yang diperoleh benar.

Berdasarkan studi literatur
yang dilakukan, beberapa teori
menunjukkan bahwa untuk
menghasilkan iklan yang baik dan
memiliki daya tarik, harus ada unsur-
unsur kreativitas di dalamnya sehingga
dapat menarik orang untuk menonton
iklan tersebut.Peran pendukung
(endorser), musik, unsur humor,
informasi, dan lain- lain didalam iklan
menjadi hal yang penting untuk
diperhatikan.Berdasarkan hasil
wawancara yang dilakukan, ditemukan
kesamaan hal-hal yang dianggap
penting oleh responden. Hampir
semua responden memiliki pendapat
yang sama mengenai pentingnya hal-
hal diatas untuk dapat menarik mereka
menonton iklan sampai selesai.
Perbedaan yang ada hanya terletak
pada preferensi masing-masing
responden terhadap hal-hal tersebut.

\section{Teknik Analisis Data}

Dalam penelitian ini, hasil wawancara akan dianalisis dengan cara diuraikan, dideskripsikan dan disimpulkan secara kualitatifpada aspek mengenai faktorfaktor penting dalam pembuatan suatu iklan agar menarik viewers untuk menonton iklan sampai selesai.

\section{Objek Penelitian}

1. Unit Analisis

Unit yang akan dianalisis dalam penelitian ini adalah pengguna YouTube di Jakarta dan Bandung yang dibagi berdasarkan golongan usia dan jenis kelamin yang familiar dengan berbagai jenis iklan yang sering muncul di website YouTube.

\section{Profil Perusahaan}

YouTube adalah sebuah situs web berbagi video yang dibuat oleh tiga mantan karyawan PayPal pada Februari 2005. Situs ini memungkinkan pengguna mengunggah, menonton, dan berbagi video.Perusahaan ini berkantor pusat di San Bruno, California, dan memakai teknologi Adobe Flash Video dan HTML5 untuk menampilkan berbagai macam konten video buatan pengguna, termasuk klip film, klip TV, dan video musik. Selain itu ada pula konten amatir seperti blog video, video orisinal pendek, dan video pendidikan.

Kebanyakan konten di YouTube diunggah oleh individu, meskipun perusahaan-perusahaan media seperti CBS, BBC, Vevo, Hulu, dan organisasi lain sudah menggunggah material mereka ke situs ini sebagai bagian dari program kemtraan YouTube. Pengguna tak terdaftar dapat menonton video, sementara pengguna terdaftar dapat menggunggah video dalam jumlah tak terbatas. 


\section{Hasil Penelitian dan Pembahasan}

Peneliti menganalisis data yang dikumpulkan melalui wawancara terstruktur kepada responden secara kualitatif dan diklasifikasi berdasarkan golongan usia dan jenis kelamin. Berdasarkan hasil wawancara tersebut didapatkan jawaban dan pendapat responden mengenai iklan yang sekarang ini sering beredar di website YouTube.

1. Analisis Faktor-Faktor Iklan yang Membuat Viewers Tidak Menonton Iklan True View In-Stream Ads di Website YouTube sampai selesai

Hasil wawancara menunjukan bahwa terdapat perbedaan pendapat mengenai alasan responden enggan menonton iklan True View In-Stream Ads yang tampil pada YouTube.Beberapa responden dengan usia relatif muda mengatakan bahwa iklan yang sering muncul tidak menarik karena tidak memiliki alur cerita yang jelas. Iklan hanya mempromosikan produk yang sama dan sudah diketahui sehingga tidak menarik minat untuk menonton iklan lebih lanjut lagi. Iklan dianggap mengganggu karena muncul secara tibatiba dengan musik yang kencang dan membuat ingin cepat di skip.

Bagi responden usia dewasa, mereka sering tidak tertarik menonton iklan tersebut karena seringkali dianggap tidak berbobot. Iklan tidak dapat memberikan sesuatu yang berarti baik informasi maupun pengetahuan bagi penontonnya sehingga dianggap menonton iklan hanyalah membuang waktu.Durasi iklan yang dianggap terlalu lama juga menjadi salah satu alasan yang diutarakan mengapa mereka tidak mau menonton iklan sampai selesai.

\section{Hasil Wawancara Responden}

Hasil wawancara diuraikan pada tabel dibawah ini: 
Tabel 4

Hasil Wawancara Dengan Responden Berdasarkan Jenis Kelamin dan Penggolongan Usia

\begin{tabular}{|c|c|c|c|c|c|}
\hline Indikator & Jenis Kelamin & Usia 12-21 & Usia 22-31 & Usia 32-41 & Usia 42-51 \\
\hline \multirow{2}{*}{$\begin{array}{l}\text { Pendukung Iklan } \\
\text { (Endorser) X1 }\end{array}$} & Pria & $\begin{array}{l}\text { Menarik, terkenal, } \\
\text { terampil } \\
\text { menyampaikan pesan }\end{array}$ & $\begin{array}{l}\text { Menarik, terkenal, } \\
\text { berhubungan dengan } \\
\text { produk, pintar }\end{array}$ & $\begin{array}{l}\text { Menarik, } \\
\text { semangat, memiliki } \\
\text { value, memahami } \\
\text { produk }\end{array}$ & $\begin{array}{l}\text { Atraktif, terkenal, sesuai } \\
\text { dengan karakter produk } \\
\text { di dalam iklan }\end{array}$ \\
\hline & Wanita & $\begin{array}{l}\text { Menarik, sedang naik } \\
\text { daun, } \\
\text { membosankan }\end{array}$ & $\begin{array}{l}\text { Dikenal publik, smart, } \\
\text { mampu } \\
\text { menyampaikan pesan } \\
\text { dengan baik }\end{array}$ & $\begin{array}{l}\text { Terkenal, memliki } \\
\text { reputasi yang baik, } \\
\text { terpercaya, } \\
\text { penampilan menarik }\end{array}$ & $\begin{array}{l}\text { Terkenal, menarik, } \\
\text { kemampuan } \\
\text { mempromosikan produk }\end{array}$ \\
\hline \multirow[b]{2}{*}{$\begin{array}{l}\text { Jalan Cerita Iklan } \\
\text { X2 }\end{array}$} & Pria & $\begin{array}{ll}\text { Konten menarik, unik, } \\
\text { durasi maksimal } 20 \\
\text { detik }\end{array}$ & $\begin{array}{l}\text { Berbobot, update, } \\
\text { menarik, } \\
\text { menginspirasi, durasi } \\
\text { maksimal } 10 \text { detik }\end{array}$ & $\begin{array}{l}\text { Menarik, membuat } \\
\text { penasaran, unik, } \\
\text { durasi maksimal } 20 \\
\text { detik }\end{array}$ & $\begin{array}{l}\text { Lugas, bermakna, penuh } \\
\text { tebakan, mendetail, } \\
\text { durasi maksimal } 20 \\
\text { detik }\end{array}$ \\
\hline & Wanita & $\begin{array}{l}\text { Menarik, bermakna, } \\
\text { tidak mudah ditebak, } \\
\text { singkat, berwawasan, } \\
\text { durasi maksimal } 10 \\
\text { detik }\end{array}$ & $\begin{array}{l}\text { Menarik, bermakna, } \\
\text { kreatif, menginspirasi, } \\
\text { tidak terduga, durasi } \\
\text { maksimal } 15 \text { detik }\end{array}$ & $\begin{array}{l}\text { Sesuai tujuan, } \\
\text { menarik, lucu, } \\
\text { berbeda, } \\
\text { mengedukasi, singkat, } \\
\text { durasi maksimal } 5 \\
\text { detik }\end{array}$ & $\begin{array}{l}\text { Unik, mendidik, jelas, } \\
\text { membangun, bermakna, } \\
\text { singkat, durasi } \\
\text { maksimal } 40 \text { detik }\end{array}$ \\
\hline $\begin{array}{l}\text { Menarik (Appealing) } \\
\text { X3 }\end{array}$ & Pria & $\begin{array}{l}\text { Nama brand ada dalam } \\
\text { iklan, latar sesuai } \\
\text { produk, eyecatching }\end{array}$ & $\begin{array}{l}\text { Nama brand ada dalam } \\
\text { iklan, latar profesional, } \\
\text { alami }\end{array}$ & $\begin{array}{l}\text { Nama brand } \text { ada } \\
\text { dalam iklan, latar } \\
\text { alam, konsep sesuai } \\
\text { dengan tema }\end{array}$ & $\begin{array}{l}\text { Nama brand ada dalam } \\
\text { iklan, latar alam, } \\
\text { kontras, terang, sesuai } \\
\text { dengan produk }\end{array}$ \\
\hline
\end{tabular}


Jurnal Akuntansi Maranathan Volume 11 Nomor 1, Mei 2019 :98 - 114

\begin{tabular}{|c|c|c|c|c|c|}
\hline & Wanita & $\begin{array}{l}\text { Nama brand ada dalam } \\
\text { iklan, latar menarik dan } \\
\text { tidak mainstream, } \\
\text { alam, sesuai produk }\end{array}$ & $\begin{array}{l}\text { Nama brand ada dalam } \\
\text { iklan, latar bagus, } \\
\text { cerah, enak dipandang, } \\
\text { alam }\end{array}$ & $\begin{array}{llr}\text { Nama } & \text { brand } & \text { ada } \\
\text { dalam } & \text { iklan, } & \text { latar } \\
\text { visual } & \text { bagus, } & \text { HD, } \\
\text { sesuai dengan produk }\end{array}$ & $\begin{array}{l}\text { Nama brand ada } \\
\text { iklan, latar } \\
\text { konteks cerita, alam, } \\
\text { cerah dan menarik } \\
\text { perhatian }\end{array}$ \\
\hline \multirow{2}{*}{ Minat (Interest) X4 } & Pria & $\begin{array}{l}\text { Ada unsur kebaruan, } \\
\text { iklan berhubungan } \\
\text { dengan minat dan } \\
\text { ketertarikan }\end{array}$ & $\begin{array}{l}\text { Ada unsur kebaruan, } \\
\text { iklan berhubungan } \\
\text { dengan minat dan } \\
\text { ketertarikan }\end{array}$ & $\begin{array}{l}\text { Ada unsur kebaruan, } \\
\text { iklan berhubungan } \\
\text { dengan minat dan } \\
\text { ketertarikan }\end{array}$ & $\begin{array}{l}\text { Ada unsur kebaruan, } \\
\text { iklan berhubungan } \\
\text { dengan minat dan } \\
\text { ketertarikan }\end{array}$ \\
\hline & Wanita & $\begin{array}{l}\text { Ada unsur kebaruan, } \\
\text { iklan berhubungan } \\
\text { dengan minat dan } \\
\text { ketertarikan }\end{array}$ & $\begin{array}{l}\text { Ada unsur kebaruan, } \\
\text { iklan berhubungan } \\
\text { dengan minat dan } \\
\text { ketertarikan }\end{array}$ & $\begin{array}{l}\text { Ada unsur kebaruan, } \\
\text { iklan berhubungan } \\
\text { dengan minat dan } \\
\text { ketertarikan }\end{array}$ & $\begin{array}{l}\text { Ada unsur kebaruan, } \\
\text { iklan berhubungan } \\
\text { dengan minat dan } \\
\text { ketertarikan }\end{array}$ \\
\hline \multirow[b]{2}{*}{ Bahasa (X5) } & Pria & $\begin{array}{l}\text { Bahasa yang santai, } \\
\text { baik, mudah } \\
\text { dimengerti, font jelas, } \\
\text { simple }\end{array}$ & $\begin{array}{l}\text { Bahasa menarik, } \\
\text { sesuai dengan produk, } \\
\text { font secukupnya, tidak } \\
\text { norak }\end{array}$ & $\begin{array}{l}\text { Bahasa sehari-hari, } \\
\text { sedikit formal, font } \\
\text { normal, unik, sesuai } \\
\text { konsep }\end{array}$ & $\begin{array}{l}\text { Bahasa baik dan benar, } \\
\text { mudah dimengerti, } \\
\text { sesuai dengan produk }\end{array}$ \\
\hline & Wanita & $\begin{array}{l}\text { Bahasa Indonesia atau } \\
\text { Inggris, singkat, jelas, } \\
\text { dapat dimengerti, font } \\
\text { sesuai tema }\end{array}$ & $\begin{array}{lr}\text { Sesuai konteks } & \text { sehari- } \\
\text { hari, } & \text { mudah } \\
\text { dimengerti, } & \\
\text { berintonasi, } & \text { font } \\
\text { menarik } & \end{array}$ & $\begin{array}{l}\text { Enak didengar, baik, } \\
\text { sopan, jelas, font } \\
\text { sesuai background, } \\
\text { mudah dibaca }\end{array}$ & $\begin{array}{l}\text { Sesuai tema, sopan, } \\
\text { bahasa sehari-hari, } \\
\text { mudah dimengerti, font } \\
\text { jelas, mudah terbaca }\end{array}$ \\
\hline & & & & & \\
\hline & & & & & \\
\hline
\end{tabular}




\begin{tabular}{|c|c|c|c|c|c|}
\hline Indikator & Jenis Kelamin & Usia 12-21 & Usia 22-31 & Usia 32-41 & Usia 42-51 \\
\hline \multirow{2}{*}{$\begin{array}{l}\text { Musik dan Gambar } \\
\text { X6 }\end{array}$} & Pria & $\begin{array}{l}\text { Musik santai, trend, } \\
\text { sesuai konten, gambar } \\
\text { menarik, resolusi tinggi }\end{array}$ & $\begin{array}{l}\text { Musik ngebeat, catchy } \\
\text { sesuai tema iklan, } \\
\text { gambar jelas, editan } \\
\text { tidak berlebihan }\end{array}$ & $\begin{array}{l}\text { Musik catchy, mudah } \\
\text { diingat, gambar HD, } \\
\text { mudah dicerna }\end{array}$ & $\begin{array}{l}\text { Musik ngebeat, enak } \\
\text { didengar, sesuai iklan, } \\
\text { gambar } \\
\text { berkualitas baik }\end{array}$ \\
\hline & Wanita & $\begin{array}{l}\text { Sesuai iklan, tenang, } \\
\text { enak didengar, } \\
\text { terkenal, gambar bagus } \\
\text { dan jelas }\end{array}$ & $\begin{array}{l}\text { Catchy, kekinian, } \\
\text { sesuai produk, gambar } \\
\text { bagus, berkualitas } \\
\text { tinggi }\end{array}$ & $\begin{array}{l}\text { Enak didengar, sesuai } \\
\text { jalan cerita, gambar } \\
\text { HD, jelas dan enak } \\
\text { dilihat }\end{array}$ & $\begin{array}{l}\text { Sesuai tema, enak } \\
\text { didengar, menguras } \\
\text { emosi, meneduhkan, } \\
\text { gambar unik }\end{array}$ \\
\hline \multirow{2}{*}{$\begin{array}{l}\text { Kepercayaan, } \\
\text { Emosional, dan } \\
\text { Pengetahuan X7 }\end{array}$} & Pria & $\begin{array}{l}\text { Sesuai dengan realita, } \\
\text { menyentuh, menghibur, } \\
\text { pengetahuan baru }\end{array}$ & $\begin{array}{l}\text { Sesuai kenyataaan, } \\
\text { masuk akal, trend, } \\
\text { menginspirasi, } \\
\text { pengetahuan baru }\end{array}$ & $\begin{array}{lr}\text { Jujur, } & \text { tidak } \\
\text { berlebihan, } \\
\text { membangun } \\
\text { mendidik, } \\
\text { produk }\end{array}$ & $\begin{array}{l}\text { Sesuai janji produk, } \\
\text { masuk akal, bermakna, } \\
\text { tentang produk, contoh } \\
\text { nyata }\end{array}$ \\
\hline & Wanita & $\begin{array}{l}\text { Didukung riset, } \\
\text { terkenal, ada testimoni, } \\
\text { menyentuh, hal-hal } \\
\text { baru }\end{array}$ & $\begin{array}{l}\text { Testimoni, aktor } \\
\text { populer, visualisasi, } \\
\text { tentang masyarakat, } \\
\text { menyentuh, hot topic }\end{array}$ & $\begin{array}{l}\text { Visual, aktor, musik, } \\
\text { cerita, kemanusiaan, } \\
\text { fakta, produk }\end{array}$ & $\begin{array}{lr}\begin{array}{l}\text { Sesuai } \\
\text { terkenal, }\end{array} & \text { kenyataan, } \\
\text { bermakna, } & \text { humanity, } \\
\text { mengedukasi } & \end{array}$ \\
\hline \multirow{2}{*}{$\begin{array}{l}\text { Bahan Pembicaraan } \\
\text { (Socialbility) X8 }\end{array}$} & Pria & $\begin{array}{l}\text { berhubungan dengan } \\
\text { kehidupan sehari-hari, } \\
\text { lucu, unik, menghibur }\end{array}$ & $\begin{array}{l}\text { Menarik, unik, lucu, } \\
\text { banyak } \\
\text { pengetahuannya }\end{array}$ & $\begin{array}{l}\text { Menarik, } \\
\text { meyakinkan, } \\
\text { kekinian, pesan } \\
\text { moral, unsur komedi }\end{array}$ & $\begin{array}{l}\text { Unik, beda, memberi } \\
\text { pengetahuan, kreatif }\end{array}$ \\
\hline & Wanita & Eyecatching, lucu, unik & $\begin{array}{l}\text { Lucu, kontroversial, } \\
\text { menarik penonton }\end{array}$ & $\begin{array}{l}\text { Meaningful, } \\
\text { menawarkan solusi, } \\
\text { real, singkat, lucu, } \\
\text { menarik }\end{array}$ & $\begin{array}{l}\text { Kontroversial, } \\
\text { kemasyarakatan, unik, } \\
\text { menggugah emosi }\end{array}$ \\
\hline
\end{tabular}




\begin{tabular}{|c|c|c|c|c|c|}
\hline \multirow{2}{*}{$\begin{array}{l}\text { Animasi dan Jingle } \\
\text { X9 }\end{array}$} & Pria & $\begin{array}{l}\text { Kreatif, profesional, } \\
\text { simpel, jingle catchy, } \\
\text { ceria, mudah diingat, } \\
\text { timing di awal video }\end{array}$ & $\begin{array}{l}\text { Rapi, special effect } \\
\text { bagus, jingle catchy, } \\
\text { easy listening, mudah } \\
\text { diingat, timing di awal } \\
\text { video }\end{array}$ & $\begin{array}{l}\text { Tidak berlebihan, full } \\
\text { colour, jingle } \\
\text { memiliki kata dan } \\
\text { musik yang catchy, } \\
\text { mudah diingat, timing } \\
\text { di awal video }\end{array}$ & $\begin{array}{l}\text { Kreatif, menarik, jingle } \\
\text { singkat, humoris, unik, } \\
\text { mudah diingat } \\
\text { penonton, timing tidak } \\
\text { berpengaruh }\end{array}$ \\
\hline & Wanita & $\begin{array}{l}\text { Rapi, lucu, jingle } \\
\text { catchy, soft, singkat, } \\
\text { timing di awal video }\end{array}$ & $\begin{array}{l}\text { Sesuai topik, unik, } \\
\text { jingle catchy, mudah } \\
\text { diingat, timing di awal } \\
\text { video }\end{array}$ & $\begin{array}{l}\text { Teknik pengambilan } \\
\text { gambar, teknik } \\
\text { fotografi, jingle enak } \\
\text { didengar, timing di } \\
\text { awal video }\end{array}$ & $\begin{array}{l}\text { Sesuai cerita, lucu, } \\
\text { jingle enak didengar, } \\
\text { atraktif, menarik, timing } \\
\text { di awal video }\end{array}$ \\
\hline \multirow{2}{*}{$\begin{array}{l}\text { Informatif } \\
\text { (Perceived } \\
\text { Informative Value) } \\
\text { X10 }\end{array}$} & Pria & $\begin{array}{lr}\begin{array}{l}\text { Uptodate, } \\
\text { informasi } \\
\text { produk }\end{array} & \text { tentang } \\
\end{array}$ & $\begin{array}{lr}\text { Informasi } & \text { tentang } \\
\text { produk dan } & \text { tidak } \\
\text { bertele-tele } & \end{array}$ & $\begin{array}{lr}\text { Informasi } & \text { penting, } \\
\text { informasi } & \text { produk, } \\
\text { bermanfaat untuk } \\
\text { kehidupan nyata }\end{array}$ & $\begin{array}{ll}\text { Informasi } & \text { produk } \\
\text { disampaikan } & \text { dengan } \\
\text { jelas baik secara visual } \\
\text { maupun audio }\end{array}$ \\
\hline & Wanita & $\begin{array}{l}\text { Informasi tentang } \\
\text { produk, relevan dengan } \\
\text { kehidupan sekarang, } \\
\text { informasi baru }\end{array}$ & $\begin{array}{l}\text { Informasi tentang } \\
\text { produk, tepat sasaran, } \\
\text { mudah dimengerti }\end{array}$ & $\begin{array}{lr}\text { Informasi } \quad \text { tentang } \\
\text { produk, informasi } \\
\text { yang meaningful }\end{array}$ & $\begin{array}{lr}\text { Informasi } & \text { tentang } \\
\text { produk, } & \text { informasi } \\
\text { terbaru } & \end{array}$ \\
\hline Indikator & Jenis Kelamin & Usia 12-21 & Usia 22-31 & Usia 32-41 & Usia 42-51 \\
\hline \multirow{2}{*}{ Quotes X11 } & Pria & $\begin{array}{l}\text { Menimbulkan rasa } \\
\text { penasaran, } \\
\text { berhubungan } \\
\text { produk, unik }\end{array}$ & Tidak berpengaruh & $\begin{array}{l}\text { Simple tetapi mudah } \\
\text { diingat }\end{array}$ & $\begin{array}{l}\text { Simple, relevan dengan } \\
\text { kehidupan sehari-hari, } \\
\text { memotivasi, } \\
\text { pembuatnya terkenal, } \\
\text { sesuai dengan produk }\end{array}$ \\
\hline & Wanita & $\begin{array}{l}\text { Membangun, simple, } \\
\text { earcatching, } \\
\text { mengajarkan tentang } \\
\text { kehidupan }\end{array}$ & $\begin{array}{l}\text { Quotes yang mudah } \\
\text { diingat }\end{array}$ & $\begin{array}{l}\text { Berkaitan dengan } \\
\text { iklan, bagus, dikenal, } \\
\text { jelas, membesarkan } \\
\text { hati }\end{array}$ & $\begin{array}{l}\text { Singkat, jelas, menarik, } \\
\text { mencerminkan produk }\end{array}$ \\
\hline
\end{tabular}




\section{Analisis Hasil Wawancara}

a. Analisis Kelompok Pria

Kelompok pria secara keseluruhan kelompok umur menginginkan peran pendukung iklan atau endorser yang berpenampilan menarik, good looking atau enak lihat, memiliki reputasi yang baik, dan mampu menyampaikan pesan dari produk yang diinginkan dengan cara yang unik. Jalan cerita pada iklan harus menampilkan konten yang menarik dan menimbulkan rasa penasaran. Bagi kelompok usia 22-31 dan 42-51 tahun jalan cerita perlu memiliki unsur pengetahuan, moral, dan berbobot. Mereka juga mengatakan bahwa iklan sebaiknya lugas dan tepat sasaran. Seluruh kelompok usia menyebutkan bahwa nama brand penting untuk disebutkan dalam iklan untuk memudahkan konsumen mengingat da mengenai brand. Latar iklan disesuaikan dengan jenis produk dan segmentasi pasar. Kelompok usia 22-31 dan 31-41 tahun menginginkan latar yang bersifat alami, berkaitan dengan luar ruangan atau pemandangan.

Seorang penonton memiliki minat untuk menonton video jika memiliki unsur kebaruan dan unsur kreativitas.Juga seluruh kelompok umur menyebutkan iklan harus memiliki hubungan dengan midat dan ketertarikan masyarakat. Kelompok usia 22-31 tahun menyebutkan unsur lain yang dapat menarik minat yakni berhubungan dengan adventure. Bahasa merupakan aspek yang jua penting dalam sebuah video. Masing-masing kelompok usia memiliki jawaban yang berbeda dimana usia 12-21 tahun menginginkan Bahasa seharihari yang mudah diingat, dimengerti, dan enak didengar; kelompok usia 22-31 tahun menambahkan unsur subtitle jika menggunakan Bahasa asing; kelompok usia 32-41 tahun memilih Bahasa formal namun tetap dimengerti; dan kelompok usia 4251 tahun memilih Bahasa Indonesia yang baik dan benar. Jika menggunakan Bahasa asing, sebaiknya tetap mudah dipahami.

Musik dan gambar merupakan dua elemen yang tidak dapat dipisahkan dalam sebuah video.Terdapat dua jawaban berbeda dari setiap kelompok umur. Kelompok usia 12-21 dan 32-42 tahun memilih musik yang santai, tidak berisik, dan tidak terlalu ramai. Sedangkan kelompok usia 22-31 dan 42-51 tahun memilih music yang up beat dan mengikuti musik yang sedang trend. Secara khusus kelompok usia 41-51 tahun juga memilih jenis musik oldies sesuai dengan karakter iklan yang dibuat. Untuk gambar seluruh kelompok usia menginginkan kualitas gambar yang jernih, bagus, jelas dengan resolusi yang tinggi. Sebuah iklan perlu menampilkan penjelasan mengenai produk sesuai dengan realita dan tidak berlebihan.Tidak hanya itu, juga harus memiliki unsur pengetahuan, serta mengandung unsur emosi. Iklan bisa menjadi bahan pembicaraan dikalangan penonton jika memuat cerita atau konten yang dihubungkan dengan kehidupan sehari-hari, berkaitan dengan topik yang hangat dibicarakan, dan bagi kelompok usia 22-31 tahun harus menarik dan berbeda dari iklan sebelumnya.

Animasi yang kreatif menjadi sebuah daya tarik bagi kelompok usia 12-21 dan 42-51 tahun dalam menonton iklan video, termasuk kelompok usia 22-31 yang menyebutkan bahwa special effect yang disajikan dalam sebuah video iklan menarik untuk ditonton. Berbeda dengan ketiga kelompok 
tersebut, usia 32-41 tahun menyampaikan bahwa animasi tidak perlu banyak yang terpenting adalah bisa memberi nilai lebih pada iklan. Bagi seluruh kelompok usia, jingle yang catchy yakni enak didengar, ceria dan mudah diingat menjadi daya tarik bagi mereka untuk menonton video hingga selesai. Iklan sebagai media promosi perlu memberikan informasi yang informatif bagi konsumen. Dalam iklan video seluruh kelompok usia merasa tertarik jika iklan memberikan informasi mengenai keunggulan dan fungsi produk secara jelas. Elemen terakhir sebagai pendukung dalam iklan video adalah quotes. Berdasarkan hasil wawancara menunjukkan hasil yang berbeda dimana usia 12-21 tahun menginginkan quotes berupa katakata mutiara yang bersifat inspirasional. Tidak hanya itu, quotes pun perlu memiliki hubungan dengan produk yang diiklankan. Kelompok usia 22-31 tahun merasa bahwa quotes tidak penting dalam sebuha video iklan. Simple dan mudah diingat menjadi syarat quotes yang diinginkan oleh kelompok umur 32-41 tahun. Sedangkan kelompok usia 42-51 tahun menyebutkan bahwa quotes sebaiknya berasal dari orang terkenal dengan tujuan meyakinkan penonton terhadap produk yang diiklankan.

b. Analisis Kelompok Wanita

Hasil wawancara kepada responden wanita, menunjukkan bahwa keseluruhan kelompok usia menjawab figur endorser harus menarik dan terkenal. Selanjutnya kelompok usia 32-41 tahun menambahkan bahwa seorang endorser harus memiliki reputasi yang baik, kredibel dan terpercaya karena mereka adalah ikon dari produk yang diiklankan. Jalan cerita yang unik, tidak mudah ditebak, dan mengejutkan akan menarik penonton untuk menonton video hingga akhir. Kelompok usia 32-41 dan 42-51 tahun pun menyampaikan bahwa sebaiknya jalan cerita dalam iklan harus memiliki unsur edukasi yang bisa mendidik penonton. Menjadi satu hal yang penting bahwa namabrand perlu dicantumkan dalam iklan video. Latar yang sesuai konteks cerita atau produk yang diiklankan, dimana seluruh kelompok usia berpendapat yang sama yakni mereka memilih pemandangan alam sebagai latar iklan.

Unsur kebaruan perlu dimasukan dalam video agar tidak membosankan. Kelompok usia 1221 tahun menekankan unsur kebaruan perlu ada terutama pada produk baru yang dikenalkan kepada pasar. Hal ini dilakukan untuk membangun awareness penonton terhadap produk tersebut.Memiliki hubungan erat dengan minat dan ketertarikan penonton menjadi salah satu daya tarik penonton untuk menyelesaikan video hingga akhir.Bagi kelompok wanit, pemilihan Bahasa Indonesia maupun Asing tidak menjadi poin penting.Sopan, lugas, mudah dimengerti dan sesuai dengan konteks iklan merupakan hal penting yang perlu diperhatikan dalam iklan video.Begitu pula dengan unsur musik, dimana perlu terdapat kesesuaian dengan produk yang diiklankan dan jalan cerita.Terdapat beberapa genre music yang berbeda bagi setiap kelompok umur. Usia 1221 tahun memilih jenis musik pop, 22-31 musik kekinian, usia 31-41 musik yang enak didengar, dan usia 42-51 tahun memilih jenis musik pop dan jazz. Tidak dapat dipungkiri bahwa kualitas gambar pada video 
menjadi hal yang krusial.Video dengan gambar yang berkualitas tinggi, eyecathing, jelas dan tidak buram sudah pasti memiliki daya tarik yang lebih tinggi dibandingkan dengan video kualitas rendah.

Sebuah iklan videoakan memiliki daya tarik jika disajikan apa adanya tanpa berlebihan dan sesuai realita. Kelompok usia 12-21 dan 22-31 tahun menyampaikan bahwa sebuah brand dapat menambahkan testimony dalam materi iklan untuk meningkatkan kepercayaan penonton. Sedangkan kelompok usia 32-41 dan 42-51 tahun menyebutkan unsur emosional yang berkaitan dengan kemanusiaan dan lingkungan mampu menarik penonton untuk menonton video hingga akhir. Menurut kelompok usia 12-21 tahun, iklan dapat menjadi bahan pembicaraan dikalangan penonton jika mampu menarik perhatian didetik pertama dan menciptakan rasa penasaran. Sedangkan usia 2231 dan 41-51 tahun iklan yang mengandung hal krontroversial menarik penonton. Berbeda dengan ketiga kelompok tersebut, usia 32-41 tahun melihat bahwa iklan dapat menjadi bahan pembicaraan jika memiliki makna tersendiri bagi penonton, bisa menawarkan solusi dan memuat hal yang nyata. Animasi menjadi salah satu faktor yang dapat menarik penonton untuk menonton iklan video.Secara keseluruhan, kelompok wanita menginginkan iklan yang rapi, tidak berlebihan, dan sesuai dengan jalan cerita. Lebih spesifik bagi usia 12-21 tahun yang menginginkan animasi lucu dan imut dan usia 32-41 tahun yang menekankan pada teknik pengambilan gambar, fotografi, dan animasi digital.

Tidak lengkap rasanya jika sebuah iklan video tidak disertai dengan jingle. Mudah diingat menjadi pilihan utama responden kelompok wanita. Selanjutnya tiga kelompok usia yakni 12-21, 22-31, dan 32-41 memilih jingle dengan nada halus dan tidak berlebihan. Sedangkan usia 42-51 tahun lebih memilih jingle yang lincah dan atraktif. Layaknya iklan pada umumnya, iklan video perlu bersifat informatif dengan memberikan berbagai informasi mengenai produk mencakup manfaat, harga, dan keunggulan. Unsur quotes pada iklan video memiliki kriteria yang berbeda untuk setiap kategori usia. Usia 1221 quotes sebaiknya bisa mengajarkan mengenai kehidupan, 22-31 mudah diingat, 32-41 berkaitan dengan iklan, dan usia 4251 tahun menginginkan quotes yang singkat dan jelas.

\section{Simpulan dan Saran}

\section{Simpulan}

Penelitian ini dilakukan untuk mengetahui faktor-faktor iklan apa yang dapat menarik viewers (penonton) untuk menonton iklan true view in-streamads di website YouTube sampai selesai berdasarkan golongan usia dan jenis kelamin. Peneliti mengukur 11 indikator dalam iklan yaitu: pendukung iklan (Endorser), jalan cerita iklan, menarik (Appealing), minat (Interest Value), bahasa, musik dan gambar, kepercayaan, emosional, dan pengetahuan, bahan pembicaraan (Sociability), Animasi dan Jingle, Informatif (Perceived Informative Value), dan quotes.

Peneliti menemukan bahwa ternyata tidak semua indikator yang ada mempengaruhi responden untuk menonton iklan sampai selesai. Dari hasil wawancara ditemukan bahwa indikator yang lebih banyak mempengaruhi viewer adalah faktor pendukung iklan (Endorser) dan jalan cerita iklan.Terdapat beberapa indikator yang menurut setiap responden tidak terlalu 
penting dan preferensi yang berbeda tidak hanya antar golongan usia dan jenis kelamin tetapi juga bisa berbeda antar individu. Indikator quotes dianggap tidak mempengaruhi oleh golongan responden pria usia 22-31 tahun untuk menonton iklan yang muncul sampai selesai.

\section{Saran}

Berdasarkan hasil penelitian ini, peneliti menemukan beberapa saran yang dapat dijadikan masukan bagi beberapa pihak, antara lain:

1. Perusahaan

Hasil penelitian ini bisa menjadi suatu hal penting yang dapat diperhatikan oleh perusahaan saat akan membuat iklan. Perusahaan bisa mempelajari berdasarkan target customer atau audiens yang ingin dicapai karena hasil penelitian menunjukkan adanya perbedaan terhadap setiap golongan usia dan jenis kelamin. Dengan memperhatikan hal-hal yang diutarakan oleh peneliti, diharapkan iklan yang nantinya beredar di website YouTube akan lebih efektif karena ditonton sampai selesai oleh setiap viewers yang melihatnya. Perusahaan juga bisa lebih mempertimbangkan keuntungan dan kerugian yang diterima sebelum memutuskan untuk memasang iklan di website YouTube.

2. Pihak lain

Untuk penelitian selanjutnya yang memiliki topik yang sama, dapat dilakukan eksperimen apabila memungkinkan untuk membuktikan hasil penelitian yang didapat dan hasil ini bisa diuji kepada populasi yang lebih luas.

\section{Daftar Pustaka}

Dewi, N. K., Andri, G., \& Yonaldi, S. (2012). Pengaruh Iklan, CItra Merk, dan Kepuasan Konsumen terhadap Loyalitas Konsumen dalam Menggunakan Vaseline Hand and Body Lotion di Kota Padang (Studi Kasus di PT. Unilever Cabang Padang). Jurnal Manajemen dan Kewirausahaan, 3 (2), 14.

Digiday.com, "The Demographics of YouTube, in 5 Charts", http://digiday.com/platforms/demograph ics-youtube-5-charts/

Durianto, D. (2003). Invasi Pasar dengan Iklan yang Efektif. Jakarta: Gramedia Pustaka Utama.

Erlinawati. (2013). Efektifvtas iklan Fashion Lite di Harian Jawa Pos. Jurnal E-Komunikasi, 1 (1), 3-5.

Intan, T. W. (n.d.). Pengaruh Kreativitas Iklan,Kualitas Pesan Iklan,dan Daya Tarik Iklan Terhadap Sikap pada Merk Melalui Efektivitas Iklan Pada Iklan Merk "X" di Surabaya.

Kotler, P., \& Armstrong, G. (2010). Principles of Marketing. United States of America : Pearson.

Kotler, P., \& K.L, K. (2008). Manajemen Pemasaran. Jakarta : Indeks.

Krishnan, S. S., \& Sitaraman, R. K. (2013, October). Understanding the Effectiveness of Video Ads : A Measurement Study.

Lukitaningsih, A. (2013). Iklan yang Efektif Sebagai Strategi Komunikasi Pemasaran. Jurnal Ekonomi dan Kewirausahaan, 13, 116.

Rogers, S. C. (1995). How to Create Advertising That Works. Journal of Business and Industrial Marketing, 10 (2), 21-22.

Sheth, J. N., \& Sharma, A. (2005). International E-Marketing : Opportunities and Issues. Journal of International Marketing Review, 22, 612. 
Shimp, T. A. (2003). Periklanan Promosi. Jakarta: Erlangga.

Straussner, S. L., \& Phillips, N. K. (2005). The Role of Empathy in Work in Woman Offenders. International Journal of Prisoner Healths, 1 (2-4), 257.

WA, P. (n.d.). Komunikasi Persuasif.

Wei, K., T, J., \& L.W, S. (n.d.). "Online Advertising: A Study on Malaysian Consumers".

Wells, W., Burnett, J., \& Moriarty, S. (2003). Advertising: Principles and Practice (6 ed.). New Jersey: Pearson Education 